\title{
Social Change, Social Marketing and Social representations
}

Since Kotler and Zaltman introduced the term social marketing in 1971, much has been written about the subject. One of the first definitions of social marketing was the design, implementation and control of programs calculated to influence the acceptability of social ideas and involving considerations of product planning, pricing, communication, distribution and marketing research (Kotler \& Zaltman, 1973, p. 56). The concept has been put into practice and used extensively to change public behaviour and promote social change. Literature reports the effective use of social marketing to promote among many other issues environmental awareness (e.g. Maibach, 1993), sustainable behavior (e.g. McKenzie-Mohr \& Smith, 1999), health improvement (Gordon, McDermott, Stead, \& Angus, 2006), reduction in alcohol consumption (Rothschild, 2006), condom use and reproductive health (Van Rossem \& Meekers, 2007) and breastfeeding (e.g. Lomas, 2009).

\section{Limitations of the social marketing model.}

In spite of the successes which the social marketing model has achieved, it is here being argued that it has some limitations which, if addressed could increase its effectiveness. Most of the literature on social marketing considers the change of public opinion and the change of attitudes as governed by the same processes. In this chapter I will argue that this assumption may be incorrect and that the kind of social change which social marketing is expected to bring about cannot be equated with individual attitude change. Social change does not only involve a change in the privately held attitudes of individuals but it also involves a change in societal beliefs and public opinion. It is therefore essential that before applying social marketing principles, change agents should study and understand how the target adopters make sense of the proposed change on two levels: (i) on an individual level, that is how the proposed change will influence the private lives of individuals and (ii) on a societal level, that is how 
the public will perceive such a change and what public opinion will be regarding the issue. For example the promotion of donating organs after one's death has implications on two levels, public opinion and personal attitudes. If public opinion is against organ donation, the attitudes of potential donors is influenced negatively and the next-of-kin of potential donors may refuse to give permission for the organs of the family member to be donated. On the other hand if public opinion is in favour of organ donation but individuals do not have positive attitudes towards donating organs, they will not carry a donor card and will not discuss it with next-of-kin. We shall briefly be refering to the organ donation campaign held in Malta between 1996 and 2000 to illustrate some of the arguments being put forward in this chapter.

The change of public opinion and the change of individual attitudes have important implications for the theoretical underpinnings of social marketing. Much of the literature on campaign research, including that of social marketing, is very much influenced by the research on attitudes. Farr (1996) points out that the study of attitude and attitude change has developed in two different directions following trends established by two different models of social psychology, the European and the American. These different approaches resulted in different definitions of attitude. Some perceive attitudes to be shared constructs while others see attitudes as being idiosyncratic and individualistic. The theory behind social marketing is very much influenced by the American literature and hence sees attitudes as individual tendencies. It is being argued here that if social marketing incorporates both the European and the American trends in attitude research, it becomes more effective. In the next section we shall will discuss the implications of adopting a more social approach towards attitude change and social marketing by suggesting the use of social representations theory as the theoretical framework within which to design public campaigns.

The theory of social representations explains the nature of public opinion and widespread beliefs, the functions they serve and also the processes of how they work (Moscovici, 1984). It provides a framework for the model of social 
change which Kotler and Roberto put forward in 1989 when they described the Social Marketing Model in detail.

\section{Understanding the social marketing environment: the role of social representations}

It has been argued by Kotler and Roberto (1989) that the first step in any plan for social change should be the understanding of the social marketing environment. Putting this into the framework of the theory of social representations this argument can be rephrased by saying that any plan for social change should start by discovering the social representations which the public or publics have of the issue being promoted. This is where the change agents have to start. Social representations should be the point of departure. Often, social marketers use surveys to get to know public opinion. However surveys only give a partial picture. Public opinion differs from privately held opinion (Himmelweit, 1990). To understand the social marketing environment requires more than survey research.

Farr $(1990,1993)$ points out that the theory of social representations is highly relevant to the study of social change, including changes in public opinion and therefore, we are arguing, important for social marketing campaigns. Farr explains, how, for example, Herzlich's study on health and illness sheds light on why campaigns designed to increase the fluoride levels in local water supplies had failed when this issue was put to the vote at a community level. On one hand, scientists claimed that an excess of fluoride was bad for the health. On the other hand, the campaigners were proposing an increase in the fluoride level of water as a measure to reduce the incidence of dental caries. The public could not understand why one should add a "bad" chemical to water which was considered "pure" and "natural" and therefore they voted against the initiative. Farr concludes that health professionals ought to have taken into account people's conceptions of health and illness before devising such a campaign (Farr, 1993).

The study of a social phenomenon, Himmelweit (1990) argues, requires a multilevel approach at the macro as well as at the micro level. If one is to 
understand and change behaviour on a societal scale one needs to draw on a diversity of sources and gain knowledge from different sources such as experts on the subject, epidemiological statistics, trend analysis, comparative analysis about the uptake of new ideas and practices by professionals, but most of all public opinion (p. 27). Himmelweit (1990) argues that public opinion, in the context of understanding and bringing about change, becomes similar to Moscovici's social representations which enter and influence the mind of each individual but are not thought out by them. Instead they are re-thought, re-cited and re-presented (p. 80). Since social marketing involves changing public opinion and the behavior of a large group of people, the theory of social representations presents an ideal framework. This point of view advocated here is not merely a slight shift in emphasis. Rather, it has impact on every step of the social marketing process: the type of formative research, the segmentation of the target audience, the encoding of the campaign messages and the way feedback is obtained and evaluated.

Below we shall suggest four developments to the social marketing model based on social representations theory. These propositions address the social dimension of social marketing which, if applied, can make social campaigns more effective. The modifications to the social marketing model have been put in practice in the organ donation campaign which was carried out in Malta between 1996 and 2000 and their implementation will be discussed briefly. A more detailed description of this campaign and its short term and long term effects is given in Lauri (2008).

(i) Social Representations should be at the foundation of planned social change

Kotler and Roberto (1989) claim that success in marketing social ideas or practices, "requires being able to predict how the target adopters will behave. Prediction, in turn, requires knowing the processes that guide and determine the behaviour of target adopters" (p. 91). In order to understand these processes, Kotler and Roberto propose two major tasks: the analysis of the social marketing environment, and researching the target adopter population. The former involves the study of the macro-social factors that could have an effect 
on the behaviour of target adopters such as political decisions, laws, and physical and economic conditions of the country. The latter, on the other hand, involves the study of attitudes and behavioural styles of the target adopters. The model put forward by Kotler and Roberto considers these two tasks as the foundations on which the social marketers can design the social marketing strategies and plan the marketing mix.

While both analyses are of extreme importance to the understanding of social change, there is a third element which is also essential and which must be integrated into the model. This is the analysis of the macro-social environment as perceived by the target adopters - their social representations. In Kotler's model the analysis of the political, religious, legal, economic, demographic and sociocultural environment is carried out by professionals consulted by the change agents. This is what Moscovici (1984) calls the reified universe. However there is another side of the coin. These macro-social elements must also be analysed from the point of view of the target-adopters, that is, how target-adopters view the political situation of the country, how they understand the teachings of the Church, how they look upon laws and the legal system of the country, how they experience culture and traditions of their country. Moscovici calls this the consensual universe. He also points out that while sciences are the means by which we understand the reified universe, social representations are the way we understand the consensual (Moscovici, 1984, p. 22).

Moscovici argues that to understand how ordinary people create and use meanings to make sense of their world, social scientists must understand the consensual universe. When Kotler and Roberto (1989) advocate the analysis of the social marketing environment, they are advocating the analysis and understanding of the reified universe, the social marketing environment as studied and understood by experts and how experts believe these processes are influencing the target audience. However, the understanding of the consensual universe, the way the target adopters make sense of the environment in which they live, is equally important. This analysis could yield a totally different picture from that which is obtained by an objective analysis of statistics and 
legislative trends and records. The former is an objective analysis as reflected from statistical data and records, while the latter is a subjective analysis of the environment as perceived by the target adopters. This subjective analysis is separate and different from the former and is equally essential in order to predict as accurately as possible the future behaviour of the target adopters. Ignoring this crucial part of the total picture can result in a less effective campaign.

An example of this important distinction was encountered in the organ donation campaign carried out in Malta. During the pre-campaign research carried out with both the experts and the public, one major finding was that there was a mistaken perception by the public that the Church, as an institution, was against organ donation and that the Catholic religion condemned organ donation because it was desecrating the human body. The teachings of the Church in fact promoted organ donation. Had only the opinion of the religious experts been sought, the researchers would have been told that the Catholic Church supports organ donation and they would perhaps not have become aware of the misconception held by the public. Since the Church in Malta is a very influential social structure, as part of the campaign the change agents asked the bishops to issue a pastoral letter which was read in every parish explaining that the teachings of the Church not only did not condemn organ donation but that in fact it was considered a noble act.

(ii) The methodology employed during formative research should be social in nature

One of the major innovations which made the concept of social marketing different from other earlier forms of promoting a product or idea was the use of consumer research to understand the attitudes and behaviours of target groups and the social marketing environment. When Kotler first proposed the model of social marketing, he highlighted the importance of research as the basis for all major decisions. Research was proposed at every stage of the social marketing process. 
Kotler and Roberto (1989) suggested various methods to collect data, however they considered the survey as being one of the major tools. They proposed that in implementing marketing research techniques, the following questions have to be answered: Who should be surveyed? How many should be surveyed? How should the respondents be selected? How should their responses be gathered? How should their responses be interpreted? (p. 73). Such an approach to consumer research is a result of an individualist orientation to understanding and implementing social change. Survey research methods, while being highly efficient in collecting a large volume of data which can be analysed quantitatively and at a relatively low cost in time and effort, often neglects the social context and the dynamics of public opinion. To understand public opinion, surveys must be accompanied by other research tools. The scope of public opinion goes beyond the results of systematic questioning of a representative sample. 'Public opinion is manifested when by one means or another 'those in the know', ......as well as the people themselves hear of what the public thinks and feels' (Himmelweit, 1990, p. 79).

Jaspars and Fraser (1984) suggest that studying attitudes through surveys, ignores the socially-shared aspects of beliefs. They argue that within a population, people might hold different attitudes about a particular issue or subject, yet they might share the same social representations of the topic or issue on which they are holding the attitude. Traditional attitude research, which concentrates upon finding differences between subjects, ignores such socially-shared aspects: "A much better understanding can be achieved if we go beyond the manifest responses which Ss provide in many attitude surveys and concern ourselves with the representations which are implicit in these responses" (Jaspars \& Fraser, 1984, p. 122).

Similarly, Billig (1993) argues that fixed instruments of measurement, such as the questionnaire, cannot tap social representations, which are themselves fluid phenomena. Public opinion research is very often a descriptive snapshot. It is not enough for researchers to know the percentage of people favouring this or that position but they must also seek to understand how social representations 
are created and how they are transformed through usage. Billig postulates that such transformations of meanings, and the way they are transformed, cannot be captured in the thick netting of the standard opinion questionnaire. He says that "to use the pollster's measuring devices to understand these meanings would be like trying to entrap the morning mist in an elephant net" (Billig, 1993, p. 44).

In a similar vein, Farr (1993) argues that while surveys enable the researcher to identify how widespread a particular belief might be within a given population, "we need the theory of social representations to account for the dynamics of the change in public opinion and why the distribution of opinion takes the particular form it does" (p. 35). Farr (1993) points out that one of the great virtues of the theory of social representation is that it does not privilege a particular method of research. Researchers using social representations as the framework for their research, have used various methodologies to collect and analyse data: surveys, participant observation, in-depth interviews, focus groups, drawings, media analysis and even experimental studies. However because social representations are constructed through the process of interaction and communication with other people, and because these interactions and conversations are themselves shaped by people's social representations, the tools used to uncover these social representations must be social in nature.

Farr, Trutkowski, and Holzl (1996) argue that attitude theory and opinion polling are based upon a strong individualistic notion of the person. They advocate the use of discussion groups in the study of social representations and public opinion, thus restoring the social context in which individuals form opinions and express attitudes. "The shaping of public opinion is a genuinely innovative and social process i.e. it is a public matter rather than a private affair. The method of investigation should reflect the theory" (p. 23).

The theory of social representations, as proposed by Moscovici, gives importance to the information that circulates in society concerning the object of study. This is why he suggests listening to people in various settings, in pubs and cafes, in academic institutions and work places, in churches and village 
halls, in other places where people meet and talk in an informal atmosphere about the issues which are of importance to them.

This line of thinking is reflected in the arguments put forward by Farr, Trutkowski, and Holzl (1996) when they claim that focus groups are the ideal tools to study social representations because there is an equivalence between Moscovici's conception of "the thinking society" and the discussion group. They propose that the discussion group is the thinking society in miniature. When people talk in a group they generate as well as transmit opinions. This reflects the proposition put forward by Lahlou (2001) who argues that social representations theory is especially relevant for describing and understanding important issues because it takes into account the feedback loop between social constructionism and individual thought and practice (p. 162). An important tenet of the theory employed to justify the focus group as a principal method of investigation in social science is that the researcher has no prior knowledge of how the participants will represent the object of study. This requires that the discussion should be as spontaneous and natural as possible. In a focus group it is possible to explore "local knowledge and understandings" more successfully than in the one-to-one interview or questionnaire.

The debate on the social nature of research has direct implications for social marketing research. As discussed above, in social marketing, the research tool most often used to assess attitudes, behaviours and needs is the survey. It is here being suggested that a more accurate representation of social reality can be obtained if social marketers study social representations as well as attitudes. This can be done by complementing the survey with such techniques as organised focus group discussions, informal conversations, interviews, and mass media analysis. Such an approach would take into consideration not only the occurrence and frequency of particular beliefs but also how these change, develop and influence social change.

In the case of the social marketing campaign carried out in Malta to increase the number of organ donors, focus groups were used in the formative research together with a survey of the attitudes towards organ donation of a random 
sample of 400 people as well as interviews with donors, recipients and hospital staff. During the focus groups, photos were used to help elicit the social representations participants had of donors and non-donors by asking them to choose from a pool of photographs present in front of them, one photo which to them represented somebody who would donate and another photo which represented somebody who would not donate his or her organs. They were also asked to explain why they had chosen those photos and their answers were analysed. Adjectives used to describe organ donors and non-donors were then subjected to corresponding analysis. Figure 1 shows the adjectives used by participants to describe donors and non-donors before the campaign.

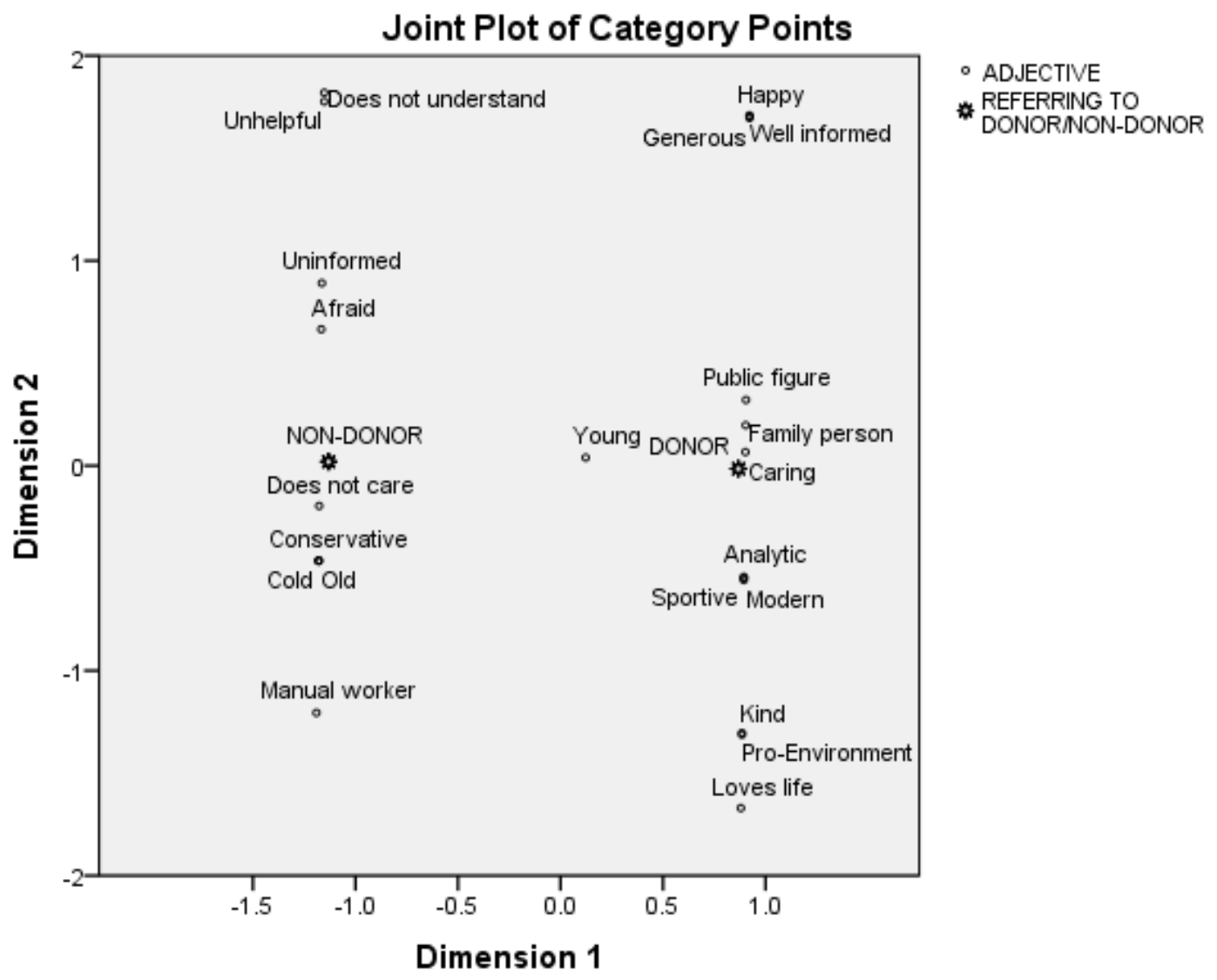

Variable Principal Normalization.

Figure 1. Adjectives used to describe donors and non-donors.

The same text was also analysed using thematic analysis. Comparing this two analysis yielded important information in that the researchers became aware of 
the metaphors used to describe organ donation (Lauri, 2009). These findings together with the analysis of the data collected through the survey and the interviews gave a reasonably accurate picture of public opinion regarding organ donation - a basis on which to design the campaign. These findings brought to light the social representations the participants had of organ donation. Some of the metaphors used by participants to describe organ donation were 'giving a gift', 'giving charity', 'giving a new life', 'recycling of body parts' and 'an insurance policy' amongst others. While finding that there was good support for organ donation, it became clear that participants lacked knowledge and that they had misconceptions. These were addressed in the campaign by choosing messages which used the same words and metaphors used by participants.

\section{(iii) Target groups should be defined in terms of social representations}

Segmenting the target-adopter population into homogeneous groups is another phase of the social marketing process proposed by Kotler and Roberto (1989). Marketers employ various criteria for segmentation. These criteria include demographics, psychographics, values and lifestyles, geographic regions, product benefits and purchase situations.

Which variables should social marketers use in segmenting their market? The answer given by Kotler and Roberto (1989) to this question is that the "most appropriate segmentation variables are those that best capture differences in the behaviour of target adopters" (Kotler \& Roberto, 1989, p. 149). They explain that in some cases, the differences in behaviour are a function of demographics. In other cases, geographic or psychographic characteristics are the primary segmentation variables. We would like to argue that there are times, indeed many times, when the variable most suitable for segmenting the target audience is the social representations which the target groups hold on the issue in question.

In such cases, segmenting the target adopter audience according to their social representations may be more relevant than segmenting them according to attitudes, beliefs and values. Members of the same target group may have 
similar attitudes and different social representations or they may have different attitudes and the same social representations. Again an example is provided by the Organ Donation Campaign held in Malta. As a result of thematic analysis of the focus group discussion, the researcher found that while the participants used different metaphors to describe organ donation, all of these metaphors stemmed from the representations participants had of their body. Figure 2 shows the three representations participants had of their body. One group believed that one's body belonged to God or a higher being who created it. Another group believed that a person owned his or her body and therefore the person was responsible for it, had to take care of it and enjoy it. A third group of people had a monistic view of the human person and did not distinguish between their physical body and their spiritual and psychological self and their identity.

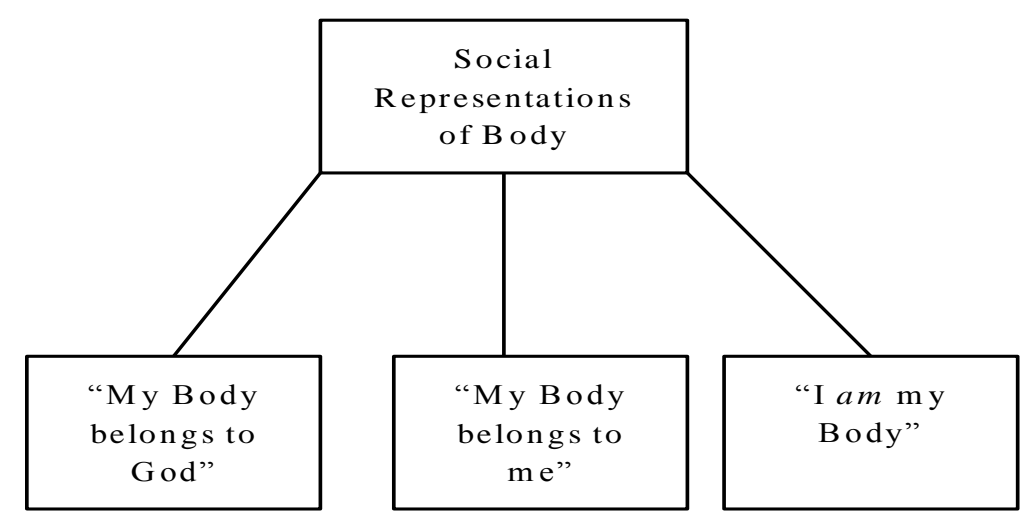

Figure 2. Representations of the human body.

Segmentation was carried out according to these three representations and messages were targeted accordingly (Table 1). For the first group who saw their body as the temple of God, the main message was that the Church encouraged organ donation and considered it a noble act. For the second group who believed that individuals owned their body, the main message was that they should make their wishes clear about whether or not they wanted to donate their organs after their death. For the third group who believed that their body was not a possession but was the actual being of the person, the main message was 
that removing parts of the body after death does not destroy the dignity and identity of the person.

\section{Table 1}

Campaign Messages for Groups with Different Social Representations of the

Body

\begin{tabular}{|c|c|c|c|}
\hline $\begin{array}{l}\text { Social } \\
\text { Representations of } \\
\text { the body }\end{array}$ & $\begin{array}{l}\text { Metaphors used to describe } \\
\text { the body }\end{array}$ & $\begin{array}{l}\text { Metaphors used to } \\
\text { describe organ donation }\end{array}$ & $\begin{array}{l}\text { Messages } \\
\text { addressed to the } \\
\text { target audience }\end{array}$ \\
\hline $\begin{array}{l}\text { Body belongs to } \\
\text { God }\end{array}$ & $\begin{array}{l}\text { Body is a sacred temple } \\
\text { Body is a gift from God } \\
\text { Body is a tool in God's hands }\end{array}$ & $\begin{array}{l}\text { Doing one's duty } \\
\text { Giving life } \\
\text { Giving a gift } \\
\text { Giving charity } \\
\text { Butchering } \\
\text { Desecrating body } \\
\text { Playing God }\end{array}$ & $\begin{array}{l}\text { Organ donation is an } \\
\text { altruistic and noble } \\
\text { act supported by the } \\
\text { teachings of the } \\
\text { Church }\end{array}$ \\
\hline I own my body & $\begin{array}{l}\text { Body is a machine } \\
\text { Body is a treasured } \\
\text { possession } \\
\text { Body is a commodity }\end{array}$ & $\begin{array}{l}\text { Recycling } \\
\text { A gift } \\
\text { Insurance policy }\end{array}$ & $\begin{array}{l}\text { Let your family } \\
\text { know of your } \\
\text { wishes; carry a } \\
\text { donor card }\end{array}$ \\
\hline I am my body & $\begin{array}{l}\text { Body is whole } \\
\text { Body is unique } \\
\text { Body is eternal }\end{array}$ & $\begin{array}{l}\text { Destruction of person's } \\
\text { identity } \\
\text { Destruction of person's } \\
\text { immortality } \\
\text { Butchery } \\
\text { Desecration } \\
\text { Living on, in another } \\
\text { person }\end{array}$ & $\begin{array}{l}\text { Organ donation } \\
\text { gives a new life to } \\
\text { recipients }\end{array}$ \\
\hline
\end{tabular}

(iv) Change agents must use group strategies to effect change

When planning social change, the problem of focusing on individual behaviour without giving due consideration to group behaviour was recognised in the 1950's by several researchers. For example Cartwright (1951) insisted that the problems he and his colleagues met in understanding the way in which people 
changed their behaviour or resisted such change, had their roots in taking the individual as "the unit of observation." Cartwright believed that it was difficult to change individuals in isolation because the pressure to conform would make it difficult for the individual to depart from the norm. Hence he believed that planned social change or, as he called it, "social management", should take this fact into consideration and thus should target groups rather than individuals.

Although Cartwright's work was carried our more than half a century ago, there are various other theories in social psychology that support his claim and that could explain why group strategies could be more effective in bringing about a change in attitudes than other strategies directed at individuals. One area of study which could explain why group strategies are more effective than individual strategies in bringing about a change in behaviour is group discussion and group decision making. Several studies carried out by researchers which formed part of the Research Centre for Group Dynamics in Michigan in the 1950 's can throw light on the issue of social influence in groups.

This American tradition of the 1950s which pre-dated notions of social marketing and stressed the importance of societal attitudes and behaviour in bringing about social change is best illustrated by the seminal study by Lewin and his colleagues when they were involved in a project to change the attitudes of the American people towards certain types of food. It is perhaps one of the very first studies about social marketing. Lewin used a number of methodologies to understand and change the behaviour of American people. One of his interventions to understand the target audience was to conduct a series of experiments with the aim of investigating the effectiveness of individual instruction versus group discussion in bringing about a change in attitudes and behaviour (Lewin, 1958). These experiments were later repeated under more carefully controlled conditions by Pennington, Harary, and Bass (1958) who found that opinion change was greater when group discussion was allowed than when no discussion took place. Group decision making, they argued, was effective in causing opinion change. It was the opportunity to discuss one's beliefs and come to a decision which helped group members change their attitude. The advantages of the group-decision method result 
primarily from the fact that group discussion facilitates decision-making and perception of consensus.

Lewin believed that it is very difficult to change individual conduct and attitudes that are rooted in groups by efforts which are directed at the individual. He claimed that "many social habits are anchored in the relation between the individuals and certain group standards. ....If the individual should try to diverge 'too much' from group standards, he would find himself in increasing difficulties. ....Most individuals, therefore stay pretty close to the groups they belong or wish to belong" (Lewin, 1958, p. 209). Planned social change which is aimed at individuals and which uses individual change strategies is bound to be less effective than one based on group strategies. The classic studies by Cartwright and Lewin indicate that, in the 40's and 50's, social psychologists had a more collective notion of attitudes. It is perhaps pertinent to reconsider these studies in a new light and apply them to changing public opinion and to social marketing.

Campaigns very often emphasise the use of mass media such as television, magazines and the Internet with the aim of reaching many people. However most of the time people use these media when they are alone. In such situations, the isolated individual is more likely to reject the message. Media campaigns based on the faulty assumptions of the magic bullet theory or the hypodermic needle model (Lasswell, 1948) may fail to bring about the desired effect. Therefore the campaign design should, as much as possible, include group strategies which encourage and facilitate group discussion and decision-making. This can be done by targeting groups through social media and interpersonal contact rather than through the traditional mass media. Talks, online chat groups, online social networks, discussions, participation in projects and other such initiatives help to encourage group members to take collective action, thus reducing the perceived risk of taking a particular decision on one's own.

The organ donation campaign in Malta aimed mainly at targeting groups. This was done through two main channels, media persons and trained group facilitators. Meetings were held with media personalities like journalists, anchor 
persons of news programmes and current affairs discussion and media owners to persuade them to help put organ donation on the public agenda. The new media were still in their infancy then and could not be used as much as one would today. Another group strategy was outreach work - going to schools and work places and holding discussion groups. Campaign volunteers with the right skills were given training on how to conduct group discussions. The main targets for these discussions were schools, work places and church groups. Various talks and discussions were held with post-secondary school children, university students, parent teachers associations, NGOs, departments in the public sector, factory workers and parish church groups. At the end of a talk and discussion, group members were encouraged to register for the organ donor card as a group initiative. Group techniques also included seminars by trained facilitators for specially targeted groups like family doctors and parish priests who were considered gate keepers as these could influence the families they came in contact with. There are indications that the messages worked. There were some changes in participants' perceptions of organ donation registered in the focus group discussions after the campaigns as seen in Table 2.

Table 3

Perceptions of Organ Donation by Potential Donors and Non-Donors Before and After the Campaign

\begin{tabular}{|l|l|l|}
\hline & $\begin{array}{c}\text { Organ donation perceived } \\
\text { less of this }\end{array}$ & $\begin{array}{c}\text { Organ donation perceived } \\
\text { more of this }\end{array}$ \\
\hline My body belongs to God & $\begin{array}{l}\text { Desecration and disrespect } \\
\text { Playing God } \\
\text { Butchery and disfigurement }\end{array}$ & $\begin{array}{l}\text { Giving life } \\
\text { Doing God's wish } \\
\text { Doing one's duty }\end{array}$ \\
\hline My body belongs to me & Giving a gift & Investment \\
\hline I am my body & Recycling & Living on \\
\hline & Disfigurement & \\
\hline
\end{tabular}


This change in attitudes and social representations had tangible results. There was an increase in the number or organs donated in the years subsequent to the campaign between 1995 and 2000. Figure 3 shows the number of organs transplanted in the years before the national campaign was launched and the years during and following the campaign. Recent statistics show that rate of donations was sustained, thanks to NGOs like Life Cycle who strive to increase awareness about organ donation.

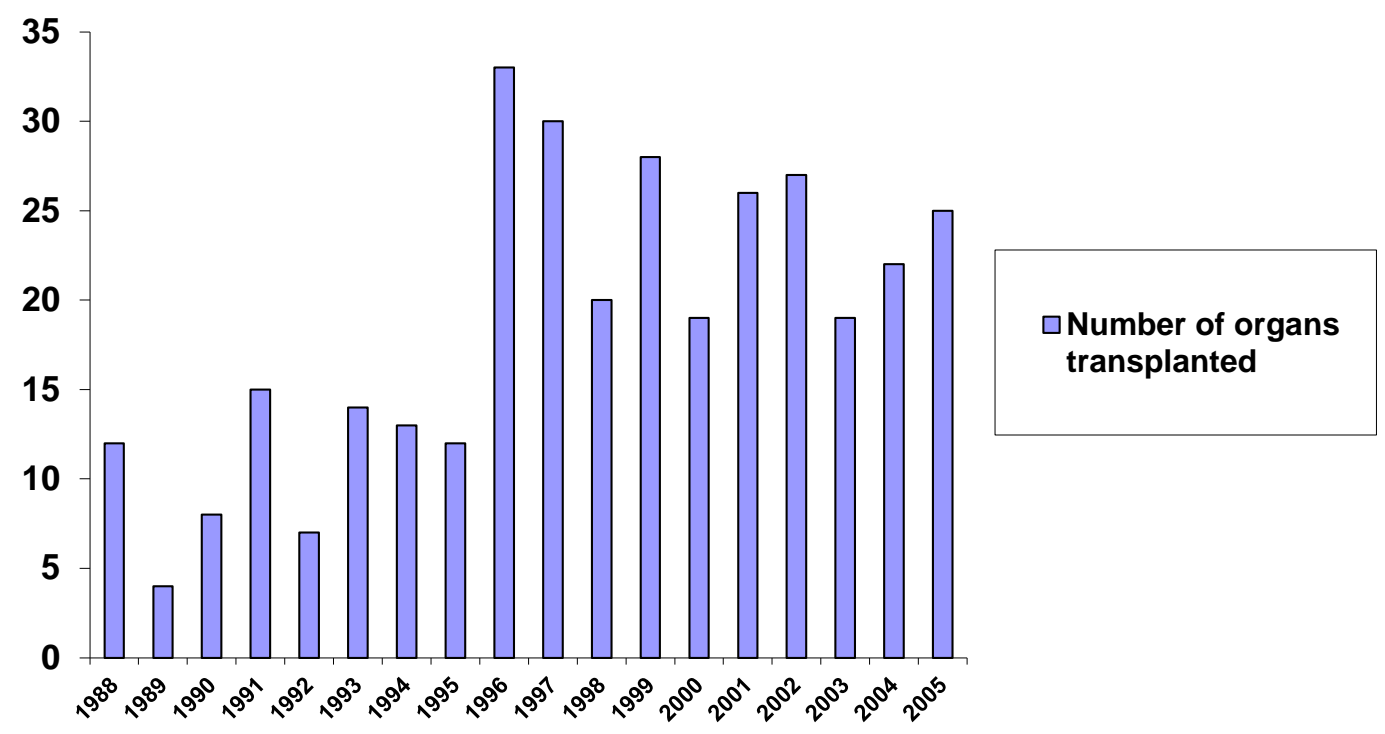

Figure 3. Number of organs transplanted from 1988 to 2005.

Source: A. Bugeja, Transplant Co-ordinator, Malta (2007, May, 12), personal communication.

\section{Conclusion}

Provencher (2011) refers to the element of surprise when analysing data in the process of a research project. Embarking on understanding the social representations of a target audience about an issue such as organ donation does 
yield surprises, and it is precisely these surprises, and how the change agents address them in designing campaigns, which make a difference whether a campaign fails or whether it is a success.

In 1947, Hyman and Sheatsley published a paper with the title, "Some reasons why information campaigns fail" in the Public Opinion Quarterly. If I had to write a paper with the same title today, we would say that one major reason why campaigns fail is because the designers of the campaign either are not aware of the social representations of the issue being marketed by the campaign, or, that if they did they failed to address them adequately.

In this discussion we have attempted to contribute to the literature on social marketing by suggesting that the model should be understood within the theoretical background of Social Representations Theory. Does this theory help us find out how to make campaigns work or why campaigns fail? we believe it does both as explained briefly above. To quote Kevin Roberts from Saatchi \& Saatchi "if you want to understand how a lion hunts, don't go to the zoo. Go to the jungle." That is the place where one can learn more about lions, lionesses and cubs (Lefebvre, 2011). It is in the jungle that we have to seek social representations, understand them and change them.

\section{References}

Billig, M. (1993). Studying the thinking society: Social representations, rhetoric, and attitudes. In G.M.Breakwell \& D.V.Canter (Eds.), Empirical approaches to social representations. Oxford: Clarendon Press. 
Cartwright, D. (1951). Some principals of mass persuasion. Achieving change in people: Some applications of group dynamics theory. Human Relations, 4, 381-392.

Farr, R. M. (1990). Social representations as widespread beliefs. In C. Fraser, \& G. Gaskell (Eds.), The social psychological study of widespread beliefs. Oxford: Clarendon Press.

Farr, R. M. (1993). Theory and method in the study of social representations. In G. M. Breakwell, \& D. V. Canter (Eds.), Empirical approaches to social representations. Oxford: Clarendon Press.

Farr, R. M. (1996). The roots of modern social psychology. Oxford: Blackwell.

Farr, R. M., Trutkowski, C., \& Holzl, E. (1996). Public opinion, group discusssion and theory of social representations. (Research Papers in Psychology, No. 9602), London School of Economics.

Gordon, R., McDermott, L., Stead, M., \& Angus, K. (2006). The effectiveness of social marketing interventions for health improvement: what's the evidence? Public Health, 120(12), 1133-1139.

Himmelweit, H. T. (1990). Societal psychology: Implications and scope. In H. T. Himmelweit, \& G. Gaskell (Eds.), Societal psychology (pp. 17-45). London: Sage.

Hyman, H., \& Sheatsley, P. (1947). Some reasons why information campaigns fail. Public Opinion Quarterly, 11(3), 412-423.

Jaspars, J. \& Fraser, C. (1984). Attitudes and social representations. In R. M. Farr, \& S. Moscovici (Eds.), Social representations (pp. 101-123). Cambridge: Cambridge University Press. 
Kotler, P. \& Roberto, E. (1989). Social marketing: Strategies for changing public behaviour. New York: Free Press.

Kotler, P. \& Zaltman, G. (1973). Social marketing: An approach to planned social change. In W. Lazer, \& E. Kelley (Eds.), Social marketing: Perspectives and viewpoints (pp. 52-69). Homewood, Illinios: Richard D. Erwin.

Lahlou, S. (2001). Functional aspects of social representations. In K. Deaux (Ed.), Representations of the social: bridging theoretical traditions (pp. 131-146). Oxford: Blackwell.

Lasswell, H. D. (1948). The structure and function of communication in society. In E. Bryson, (Ed.), The communication of ideas (pp. 37-51). New York: Harper and Brothers.

Lauri, M. A. (2008). Changing public opinion towards organ donation. A social psychological approach to social marketing. In L. O. Pietrieff, \& R. V. Miller (Eds.), Public Opinion Research Focus, pp. 9-36. New York: Nova Science Publishers.

Lauri, M. A. (2009). Metaphors of organ donation, social representations of the body and the opt-out system. British Journal of Health Psychology, 14, 647-666.

Lefebvre, R. (2011). On social marketing and social change: Selected readings 2005-2009. Seattle: CreateSpace Independent Publishing Platform.

Lewin, K. (1958). Group decision and social change. In E. E. Maccoby, T. M. Newcomb, \& E. L. Hartley (Eds.), Readings in social psychology $\left(3^{\text {rd }}\right.$ ed., pp. 197-211). New York: Henry Holt \& Co. 
Lomas, C. (2009, June 9). Beyond getting the message - why the NMS is adopting social marketing - breast feeding. NursingTimes.net. Retrieved from http://www.nursingtimes.net/whats-new-in-nursing/primarycare/beyond-getting-the-message-why-the-nhs-is-adopting-socialmarketing/5002452.article

Maibach, E. (1993). Social marketing for the environment: Using information campaigns to promote environmental awareness and behaviour change. Health Promotion International, 8 (3), 209-224.

McKenzie-Mohr, D., \& Smith, W. (1999). Fostering sustainable behaviour: An introduction to community-based social marketing. Canada: New Society Publishers.

Moscovici, S. (1984). The phenomenon of social representations. In R. M. Farr, \& S. Moscovici (Eds.), Social representations (pp. 3-69). Cambridge: Cambridge University Press.

Pennington, D. F., Harary, F., \& Bass, B. M. (1958). Some effects of decision and discussion on coalescence, change, and effectiveness. Journal of Applied Psychology, 42 (6), 404-408.

Provencher, C. (2011). Lauri on organ donation or how to teach the theory of social representations using a quality empirical study. Papers on Social Representations, 20, 35.1-35.9.

Van Rossem, R., \& Meekers, D. (2007). The search and impact of social marketing and reproductive health communication campaigns in Zambia. BMC Public Health, 7(352). doi:10.1186/1471-2458-7-352 